\title{
Development of the activity of gifted schoolchildren in mastering geometric con-cepts in figurative structures
}

\section{Desarrollo de la actividad de los escolares superdotados en el dominio de conceptos geométricos en estructuras figurativas}

\author{
Natalia G. Podaeva* \\ Bunin Yelets State University, Yelets, Russia \\ ORCID: https://orcid.org/0000-0002-9491-5011 \\ Mikhail V. Podaev \\ The Center for the Support of Gifted Children 'Strategy', Lipetsk, Russia \\ ORCID: https://orcid.org/0000-0003-1078-2838 \\ Pavel A. Agafonov \\ SBEI Secondary School No. 2070, Moscow, Russia \\ ORCID: https://orcid.org/0000-0002-8934-0233
}




\section{Summary}

Background: The relevance of developing mental activity for mastering geometric concepts relates to the change in paradigmatic foundations taking place in modern education. Such a change is associated with the recognition of a schoolchild as a subject of educational and cognitive activity, the initiator of own activity. Objective: The authors attempted to describe a model of a didactic system for developing active usage of geometric concepts in the process of teaching geometry to mathematically gifted schoolchildren in 10-11 grades. The authors also used the GeoGebra dynamic system as a component of the electronic educational environment (EEE). The objective is achieved by characterizing the architecture of the system model, which evokes active usage of geometric concepts within schoolchildren in learning situations; substantiating psychodidactic conditions for the effective development of this activity using the GeoGebra dynamic system; and defining levels, criteria, and indicators of development. Methods: A specially organized educational activity in EEE and a developed system of tasks within the framework of the elective course "Problems of solid geometry and computer graphics" for 10-11 graders represent a didactic means of developing the activities related to figurative-spatial methods of information coding. Findings: The authors described a didactic system model for mastering geometric concepts in figurative structures in the process of teaching geometry to 1011 graders using the GeoGebra dynamic system. Conclusions: Fostering schoolchildren' mastering geometric concepts in figurative structures occurs under the direct influence of teaching. However, this process is complex and internally contradictory. The structure of this kind of activity contains actions of different nature.

Keywords: socioculturally oriented geometry teaching; mental activity for mastering geometric concepts; electronic educational environment (EEE); intentional (emotional-evaluative) attitude; integral units of thinking; concept content plane.

\section{Resumen}

ANTECEDENTES: La relevancia de desarrollar la actividad mental para dominar los conceptos geométricos se relaciona con el cambio en las fundaciones paradigmáticas que tienen lugar en la educación moderna. Dicho cambio se asocia con el reconocimiento de un escolar como un tema de actividad educativa y cognitiva, el iniciador de la actividad propia. Objetivo: Los autores intentaron describir un modelo de un sistema didáctico para desarrollar el uso activo de los conceptos geométricos en el proceso de enseñar geometría a los escolares dotados matemáticamente en los grados 10-11. Los autores también utilizaron el sistema dinámico GEOGEBRA como un componente del entorno educativo electrónico (EEE). El objetivo se logra caracterizando la arquitectura del modelo del sistema, que evoca el uso activo de los conceptos geométricos dentro de los escolares en situaciones de aprendizaje; Condiciones psicodidácticas de sustanciación para el desarrollo efectivo de esta actividad utilizando el sistema dinámico GEOGEBRA; y definir niveles, criterios e indicadores de desarrollo. Métodos: una actividad educativa especialmente organizada en EEE y un sistema de tareas desarrollado en el marco del curso electivo "Problemas de geometría sólida y gráficos de computadora" para estudiantes de 10 a 11 estudiantes representan un medio didáctico para desarrollar las actividades relacionadas con los métodos figurativos-espaciales. de la codificación de la información. Hallazgos: Los autores describieron un modelo de sistema didáctico para dominar los conceptos geométricos en estructuras figurativas en el proceso de enseñanza de geometría a 10-11 estudiantes utilizando el sistema dinámico GEOGEBRA. CONCLUSIONES: Fomentar los conceptos geométricos de "dominar los escolares en las estructuras figurativas ocurre bajo la influencia directa de la enseñanza. Sin embargo, este proceso es complejo y contradictorio internamente. La estructura de este tipo de actividad contiene acciones de diferente naturaleza.

Palabras clave: enseñanza de geometría orientada a socioculturales; actividad mental para dominar los conceptos geométricos; Entorno educativo electrónico (EEE); actitud intencional (evaluativa emocional); Unidades integrales de pensamiento; Avión de contenido del concepto. 


\section{Introduction}

The relevance of developing mental activity for mastering geometric concepts in figurative structures relates to the change in paradigmatic foundations taking place in modern education. Such a change is associated with the recognition of a schoolchild as a subject of educational and cognitive activity, the initiator of own activity [40]. The subject of pedagogical research is internal resources of gifted schoolchildren that initiate and regulate their intellectual behavior. These resources include mathematical thinking, where concepts have a special place.

Psychology defines conceptual structures as mental ones resulting from the integration of the basic information-processing mechanisms - archetypal structures, methods of coding information, cognitive schemes, and semantic structures. The most important mechanism is ways of information coding, i.e. the subjective means to let a person reflect the surrounding world through their experience. As L.M. Vekker noted, information processing occurs in the intellect in the system of four experience modalities: a sign, an image (visual-spatial coding method), an objective action, and an emotional impression. The formation of intellect is based on the ability to translate from one coding method to another. Moreover, the work of the intellect of most children is characterized by the predominance of one of the four experience modalities.

Geometry as an academic subject is traditionally built on a deductive basis. The assimilation of the axiomatic method (axioms, definitions, theorems, and concepts) is effective under the condition of a developed verbal-logical modality. At the same time, the visual-spatial method of coding and the emotional impression associated with visual and intuitive ideas about geometric concepts are secondary in axiomatic geometry, being only a kind of illustration of its theoretical postulates. Such an architectonics of geometric education, corresponding to the principle of scientific character, does not correspond to the age-related laws of thinking development, such as integrity, multidimensionality, and reliance on the imaginative perception of the objective world. In this regard, I.F. Sharygin noted: "The method of coordinates is one of the most effective methods of dealing with geometry. He leaves aside the essence of the studied phenomenon. A performer is brought up who solves a given specific task. Geometric intuition, which is necessary for a mathematician-researcher, does not develop". [30] concluded that spatial thinking does not develop purposefully and systematically in a traditional geometry course. Much attention is paid to acquaintance with individual geometric figures, their properties, and relationships, mostly metric, the construction of geometric figures (and in their standard position); disappears in the practice of teaching geometry such an important methodological device as stimulating work "in the imagination".

In the context of these ideas, the study asserts the idea that the most difficult component of integrative activity for mastering concepts, which is critical for successful mastering geometry, are actions based on the visual-spatial method of coding since they are associated with diverse mental processes: perception, memory, performance, and imagination. The main operational unit of this kind of activity is an image in which the allocation of the spatial characteristics of an object - form, size, and the relationship of constituent elements, their location on a plane or in space relative to a given reference point is the central moment.

The purpose of the research is to describe the development model of activities for mastering geometric concepts in figurative structures in the process of teaching geometry to gifted schoolchildren in grades 10-11 using the resource of the GeoGebra dynamic system. The goal was achieved by characterizing the psychodidactic structure, which in the situation of teaching geometry, the assimilation by schoolchildren of figurative-spatial methods of action with geometric concepts; substantiating psychodidactic conditions for the effective development of this kind of mental activity of schoolchildren; define levels, criteria, and indicators of development; describing the results of experimental work in the framework of the elective course "Problems of solid geometry and computer graphics" for gifted schoolchildren in grades 10-11 using the resource of the GeoGebra dynamic system as a component of the electronic educational environment (EEE).

\section{Literature Review}

Currently, there is no doubt about the importance of the formation of spatial thinking for the achievement of success by schoolchildren in mastering mathematical and technical disciplines 
(A.G. Belousova, G.D. Glazer, V.A. Dalinger, H.-M.Kh. Ya. Kaplunovich, T.V. Kudryavtsev, M.A.Kholodnaya, I.S. Yakimanskaya, et al.).

Most of the modern studies on spatial thinking (for example, studies by A.V.Beloshistoy, A.V. Vasilenko, V.A. Dalinger, et al.) are of a scientific and methodological nature and are aimed at the development and systematization of tasks for mastering spatial thinking of schoolchildren in mathematics lessons $[34,35,36]$

The nature of thought processes, including their higher forms, cannot be understood without considering the role of the figurative-spatial components of its organization, which is confirmed by the fundamental research by L.M. Vekker, S.L. Rubinstein [37, 38]

Studies of spatial thinking in solving mathematical (A.G. Belousova, A.V. Beloshistaya, V.A.Dalinger, I.Ya. Kaplunovich, et al.) graphic problems (T.V.Bogoslovskaya, A.D. Botvinnikova, A.V. Vasilenko, E.N. Kabanova-Meller, I.S. Yakimanskaya, et al.), orientation in space (T.N. Voytik, A.V. Ponomarenko, A.V. Chuntul, F.N. Shemyakin, et al.), et al.

Analysis of psychological and pedagogical literature on the study, formation, and diagnosis of schoolchildren' spatial thinking allows the authors for singling out the following areas of research:

1) Spatial thinking as one of the components of mathematical abilities and talents (V. Brown, I. Verdelin, G.D. Glazer A. Cameron, V.A. Krutetsky, V.N. Myasishchev, et al.);

2) Theoretical foundations of spatial thinking, criteria, and indicators of its formation (Z.I. Kalmykova, I.Ya. Kaplunovich, N.D. Matsko I.S. Yakimanskaya, et al.);

3) Issues of diagnostics of spatial thinking and imagination (G.D. Gleizer, V.A. Dalinger, V.G. Zarkhin, H.-M.Kh. Kadayas, A. Pardala, A.E. Simanovsky, R.A. Khabib, I.S. Yakimanskaya, et al.);

4) Methods and means for the development of spatial thinking (E.R. Baklitskaya, V.G. Vladimirsky, M.R. Druzhinin, V.I.Zykova, K.I. Kambarov, V.N. Litvinenko, G.N. Nikitina, A. Pardala, S.V. Petrov, I.F. Tislenko, A.I. Fetisov, A.L. Tsukar, N.F. Chetvertukhin, et al.);

5) Age and individual characteristics of spatial thinking and its formation in different age periods (I.A. Breus, T.A. Varentsova, N.Ya. Varnavskaya, I.G. Vyaltseva, E.A. Zakharova, N.N. Zepnova, E.V. Znamenskaya, N.E. Izergina, I.P. Istomina, K.I. Kambarov, E.F. Kozina, V.I. Kokuroshnikova, I.A. Kochetkova, R.F. Mamalygina, E.V. Nikulina, E.G. Ovodova, K.G. Serdakov, N.I. Tsarkova, et al.).

H.-M.H. Kadayas, G.I. Mikshite, I.S. Yakimanskaya speak in their works about the relationship between the level of spatial thinking formation in schoolchildren and the direction of their cognitive interest [39].

\section{Methods}

Revealing the essence of developing the activities of subjects-schoolchildren to master geometric concepts, the authors note that in the framework of this study the authors focus only on the basic level of representations, which precedes the conceptual (verbal-logical) level and assumes reliance on the figurative-spatial method of coding information. It is about the development of the ability to convey the essential characteristics of geometric objects, transform a visual or mental image following the requirements of the task, develop an image in the course of reasoning, etc. in figurative forms. Moreover, this problem is not properly discussed in the traditional methodology. So, only two-dimensional objects are studied in grades 7-9, therefore, the following difficulties arise in 10th grades: schoolchildren do not know how to decode images of spatial figures (a flat image does not cause them associations with a volumetric figure-original), are not guided in practical and theoretical space, do not know how to operate with images, transform them and create new images. All of the above actualizes the problem of teaching the figurative-spatial way of mastering concepts.

Theoretically substantiating the categorical apparatus of the research, let us clarify that a geometric concept is a sign-symbolic system that includes the following components: ideal characteristics (properties, attributes); material objects and models in the real world (naturalization of a geometric concept); sign and symbolic constructions; the activity component of geometric concepts, which includes actions and operations, both formal-logical and figurative- 
meaningful - allowing to recreate an object based on various types of fixation, to include it in relationships, to obtain new objects, etc.

The study confirms the idea that the formation of concepts is directly related to the development of mental operations, general intellectual, generalized educational skills that make up the external structure of the educational and cognitive activity. In the process of concept formation, not only and not so much declarative knowledge (descriptions, messages, judgments, and statements) should be taken into account, but procedural and value-based knowledge.

Procedural knowledge (algorithms, techniques, and methods for solving problems) refers to knowledge of a practical type since their assimilation is carried out through mental experience in the course of long-term purposeful activity. Moreover, the main operational unit of this kind of activity in the field of geometry is a spatial image, in which it is possible to single out the visual, verbal-logical, and emotional components.

The visual component allows for recreating the spatial properties and relationships of a geometric object using a spatial image. The spatial image is meaningfully different from other images that can reflect the non-spatial characteristics of objects.

The verbal-logical component of the geometric image reflects the close connection of spatial representations with logical operations. The process of cognition begins with the appearance of an image and only then passes into a logical phase. The spatial image is viewed as a theoretical ideal object, which is a "logical reconstruction of reality". Its sign is that it exists only in signs and symbols and has properties that real objects do not possess. For example, a straight line, plane, and ray have the properties of unboundedness, openness, non-compactness, etc.

Finally, the emotional component reveals a leading role in the development of geometric concepts of value knowledge, which are expressed in the form of value judgments and are formed based on emotional-evaluative (intentional) experience. As pointed out by A. Poincaré, intuition and aesthetic sense play in geometry the role of a kind of sieve through which various combinations of ideas are sifted, since the most useful combinations are mathematically the most beautiful.

Thus, the development of activities for mastering geometric concepts in figurative structures occurs in the system of four modalities of experience - verbal-symbolic, visual-spatial, subject-practical, and sensory-emotional. The formation of a concept is based on the ability to translate one modality into another.

\section{Discussion}

The model of the system for developing figurative-spatial methods of activity with geometric concepts in the process of teaching geometry to schoolchildren in grades 10-11 using the GeoGebra dynamic system as part of the elective course "Problems of solid geometry and computer graphics" is integrated with the traditional learning system due to the observance of many principles: the principles of nonlinearity, individualization, meaning the ability of the methodological support system to respond to motives, individual characteristics of the schoolchild; the principle of openness, meaning that the system can integrate with other systems.

These principles make it possible to formulate the definition: the system for the development of schoolchildren' activity in the development of spatial geometric concepts is nonlinear, open, integrated with the traditional system of mathematical education, acting based on the GeoGebra.ru, which corresponds to the age patterns of the formation of the scientific concepts, is a cyclical one, and is based on the schoolchildren's personal experience, their deployment within five phases, each of which is associated with the development of figurativespatial methods of action with geometric concepts and corresponds to a certain development level. A separate learning cycle (within the framework of the formation of a certain concept) includes the following successively replacing phases: "1) primary image (percept) - 2) secondary image (generalized representation) - 3) operating with an image (preconception - image-concept) - 4) orientation in space (concept) -5) intentional (emotional-evaluative) attitude".

The development of the activity of schoolchildren in the development of spatial geometric concepts is under the direct influence of teaching. A didactic means of development is a specially organized educational activity in 3D graphics of the GeoGebra system and a bank of tasks that go 
from simple transformations of an image based on perception to more and more complex types of operations that occur in an ideal plan.

But the process of development is complex, internally contradictory, in the structure of this kind of activity some actions and operations relate both to the plane of the content of the concept and to the planes of sign form and intentional experience: actions of creating a perception based on real and practical operations; actions at the level of generalized presentation; operations of operating with geometric images; transformation of the structure of the original image, etc. The complexity and abundance of factors ensuring their formation determine the peculiarities of development. Assessment of the development level of schoolchildren' activity in mastering figurative-spatial methods of action with geometric concepts should be carried out comprehensively, taking into account its complex structure, based on indicators that are internally and closely interrelated.

When diagnosing the cognitive level, the authors relied on types of image operation identified by I.S. Yakimanskaya and I.Ya. Kaplunovich. The indicators characterizing the level of formation include:

At the image creation level:

1. Actualization of the main properties of the figure - highlighting the essential features of the object, spatial, and metric relationships.

2. Ability to compare objects by their properties.

3. Ability to mentally group individual elements of an object.

4. Species-level identification - the ability to define a figure as a carrier of a concept.

5. Extraction of data and required elements.

6. Mental reconstruction and construction of additional elements.

At the level of usage in a manner:

1. The ability to use an image based on geometric transformations: parallel translation, rotation, central and axial symmetry, symmetry about a plane, homothety (similarity), parallel projection, orthogonal projection, perspective.

2. The degree of image generalization is manifested in the ability to create images that combine topological, projective, metric properties and relationships.

3. Image denaturalization is manifested in the awareness of the differences between real (visible or imaginary) and geometric (conceptual) space.

4. The breadth of image usage is the ability to move quickly and easily from one image to another. The constraint with one image, attachment to one point of reference indicates the insufficient breadth of usage.

5. The degree of mastering the activity of including the same image in different systems of connections and relations underlying spatial transformations ("analysis through synthesis" according to S.L. Rubinstein). Fluency in this operation ensures the detection of new features in the perceived object. Insufficient knowledge limits the possibilities of transforming visual material, rethinking it, and complicates the search for a solution to the problem.

3. The degree of complexity and dynamism of the relationship between the original and the new image. A new image is created based on the original, in the course of operating by abstracting from it. The inability to abstract from the image in time, to keep its mental transformations in memory and fix them visually, without using visual support, is often a brake on finding an original way to solve a problem.

4. The dynamics of the ratio of the initial and final images. Operating an image in the process of solving a problem is determined, firstly, by visual material based on which the image arises, and secondly, by its transformations, which must be carried out based on the requirements of the problem. This double determination determines the objective difficulties in image creation.

5. The completeness of the image characterizes its constituent elements in terms of shape, size, and spatial distribution. As a rule, the reproduction of spatial relationships is carried out correctly by far from all schoolchildren who are in the same conditions.

6. The content of the spatial image is the completeness of the reflection of the spatial characteristics of the object. 
Following this, to determine the support "zones" of each schoolchild, the following levels were identified, corresponding to the phases of the cycle of mastering the activity of mastering geometric concepts in figurative structures:

1. Low reproductive level, registering the assimilation by schoolchildren of methods of action with geometric concepts at the level of perceptual creation. At the same time, they act in perceptual space, being guided "according to the body scheme", relying on real operations, naturalization of geometric objects, and intuition.

2. The average reproductive level, signaling the assimilation of methods of action with spatial concepts at the level of generalized representation. Sign naturalization is overcome, provided by another type of operation - generalization (typing).

3. High reproductive level ("movement"), corresponding to the mental operation of operating with geometric images. However, the operation refers only to the spatial location of the object and does not affect its structural features. This is the easiest level since there are no structural changes in the geometric figure - it simply moves in space: it turns, is transferred in parallel.

4. Low productive level ("reconstruction"). The structure of the original image is being transformed. Unlike movement, here the mental image undergoes a single modification of its structure - cutting, folding, etc.

5. Average productive level ("composition"). There is a transformation of both the spatial location and the structure of the image. A geometric object is modified repeatedly, while also moving in space. At this level of mastering the methods of action, it is assumed that the preconception is formed - the image-concept.

6. High productive level, corresponding to the schoolchild' ability to navigate in space "from oneself" using external (visual) reference points.

7. Low productive and creative level, implying the schoolchild's ability to navigate in space from an independently chosen reference point using internal (kinesthetic) guidelines.

8. The average productive and creative level, which presupposes the formation of the schoolchild's ability to navigate in space from an objectively given reference point using visceral landmarks.

9. High productive and creative level, which presupposes the formation of a geometric concept as a means of mental reproduction of objects, uniting the plane of the content of geometric knowledge, the plane of sign form, and intentional experience. This level corresponds to the schoolchild's ability to navigate in space from a dynamically changing reference point.

To identify which of the above types of actions with geometric concepts was formed in the schoolchild, the authors analyzed the schoolchild's work. This made it possible to identify general "failures" in the structure of activity with spatial concepts, as well as to determine a system of measures to change the situation using a special set of tasks and exercises.

We must not forget that the positive dynamics of the formation of methods of action with geometric concepts presupposes such conditions as a gradual and sequential complication of the type of operation with an image, as well as the obligatory propaedeutics of solving many problems.

After the level of formation of methods of action with geometric concepts was identified, we moved on to the study of some individual characteristics that determine the differentiation in the mastery of this type of activity by schoolchildren.

Control over the process of mastering geometric concepts by this sample of schoolchildren showed that often schoolchildren, belonging, for example, to the second level and freely solving tasks of one type, have difficulties in completing tasks of another type, also related to the second level. This can be explained by the fact that schoolchildren have to use various types of transformations of spatial images, some of which they own and others do not. At first glance, the discovered facts are paradoxical: in the process of teaching schoolchildren to act related to the second level, more visual supports and exercises in 3D graphics of the GeoGebra system are required than when mastering the first level; some schoolchildren who belong to the third level, in terms of orientation in space, may lag behind adolescents with the second level, who do not need to build configurations in the 3D graphics of the GeoGebra system. 
To explain the apparent contradictions, the authors typified all tasks into "internal" and "external". Tasks that imply the need to analyze the internal structure of a spatial figure and associated geometric quantities that are invariant under transformations that do not go beyond the given figure were classified as "internal" tasks. These can be metric problems for polyhedra, cones, cylinders. Moreover, their solution on paper or a board was preceded by the construction of a configuration in 3D graphics of the GeoGebra system. It should also be noted that at the same level and in the course of testing the same skill, it is possible to require an internal or external operation, depending on the formulation of the problem.

All tasks are typified following a cyclical structure that ensures the formation of methods of action with geometric concepts: "Primary image of perception (percept) - the secondary image of perception (generalized representation) - image operation (preconception - image-concept) orientation in space (concept) - intentional attitude ". Schematically, the phases of development of this structure are presented in the form of blocks corresponding to the levels of assimilation of the concept. The content of the blocks is determined by the above-described structure of the activity component of geometric concepts. Within the framework of this article, we will reveal the content of the stage corresponding to the fourth level "concept - orientation in space". It is supposed to master the most difficult action - orientation in space.

The complexity of tasks requiring the formation of this kind of action varies depending on the choice of the starting point. The first level of difficulty includes tasks that assume that the starting point is the schoolchild. These can be tasks for the construction of models of geometric shapes, etc.

The second level of orientation in space involves the schoolchild's ability to solve problems in which the starting point of reference is outside the subject, and it can be chosen independently. Most of the problems of solid geometry are of this type - when relying on any geometric drawing, schoolchildren have to choose a starting point.

The third level of complexity involves mastering the ability to solve solid geometry problems, in which the reference point is objectively set (fixed).

The fourth, most difficult way of orientation is orientation from an arbitrarily (freely) constantly changing point of the report. It was to it that S.L. Rubinstein attached particular importance. "The core of the general development of an understanding of space," he wrote, "is the transition from a frame of reference (coordinates) fixed in itself to a system with a freely moving reference point. Only based on this operation does the unformed experience of extension become a true perception of space" [38, p. 272].

Tasks for mastering the concept of "combining transformations" are considered. The fourth level of assimilation for this concept assumes the schoolchild's ability to determine the location or direction of movement of an object in space through external (visual) or internal (visceral, kinesthetic) landmarks. A striking example of such problems is solid geometry tasks from the profile level of the Unified State Exam in mathematics, as well as tasks from Olympiads. Such tasks are distinguished by the highest level of complexity. Spatial orientation is based on the activity of creating spatial images and on the process of operating them.

When solving this kind of problem, all kinds of transformations of the original image can be performed for a long time and repeatedly, which makes up a whole series of mental actions that replace each other. Both the spatial location of the object and the structure are being transformed. It is assumed that a geometric concept is formed as a means of mental reproduction of objects, uniting the plane of the content of geometric knowledge and the plane of the sign form. Conceptual thinking unfolds in figurative structures, while logical (formal) operations are the mechanism of unfolding.

Task. Tournament of cities. 2010/2011, spring tour, difficult option, grade 10-11.

From a beam in the form of a triangular prism, sawed-off (with a flat saw) on a piece on both sides. The cuts did not hit either the foundation or each other. a) Can cuts be similar but not equal triangles? b) Can one cut be an equilateral triangle with side 1 and the other an equilateral triangle with side 2 ?

Solution 
a) Take a non-sided triangle $\mathrm{T}$ and choose two different sides a and $\mathrm{b}$ in it. Take also a triangle $\mathrm{U}$ similar to $\mathrm{T}$ with a coefficient $\mathrm{a} / \mathrm{b}$. We attach them with sides of length so that they do not lie in the same plane. The two free vertices of these triangles define the direction of the lateral edge of the prism, which we will make large enough for the prism to have disjoint sections equal to $\mathrm{T}$ and $\mathrm{U}$.

b) Suppose that such cuts turned out. The distances between the lateral edges of the prism do not exceed the length of the side of the triangle connecting the points on these edges, that is, not more than 1. Let us assume that the side edges are vertical. Let's draw three horizontal planes through the tops of the larger saw cut. Let the second plane lie between the first and the third, and the distances from it to the other two are equal to $a$ and $b$. Then the sides of the large triangle will become the diagonals of rectangles with a width equal to the distance between the corresponding side edges, and their heights equal to $\mathrm{a}, \mathrm{b}$, and $\mathrm{a}+\mathrm{b}$. However, if the width of the rectangle with height $\mathrm{a}$ is at most 1 , and the length of the diagonal is 2 , then $\mathrm{a} \geq \sqrt{3}$. Similarly, $\mathrm{b} \geq \sqrt{3}$. Then the height of the third rectangle is $a+b \geq 2 \sqrt{3}>2$, especially since its diagonal is greater than 2 . Contradiction

Answer

a) It is possible. b) It is impossible.
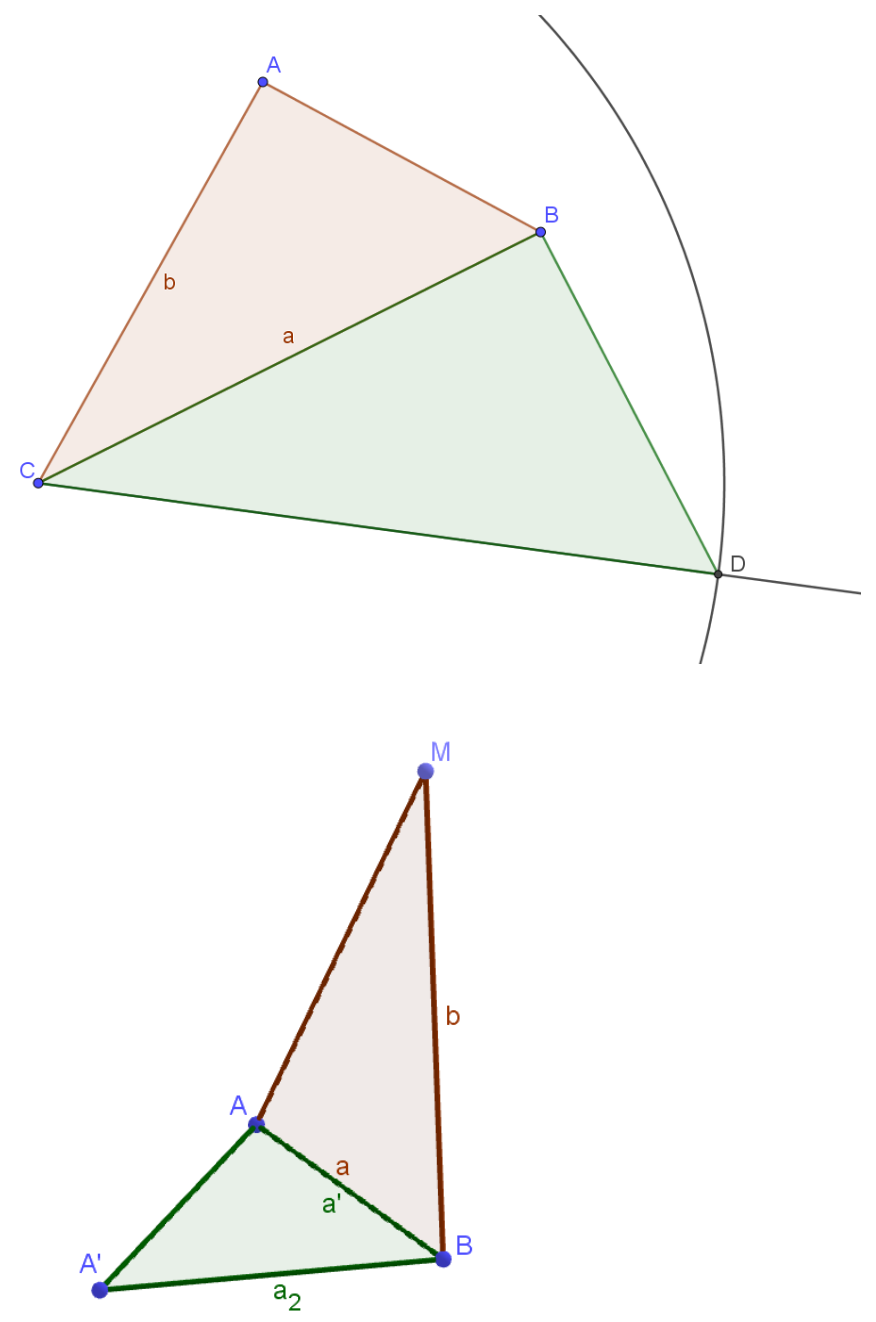


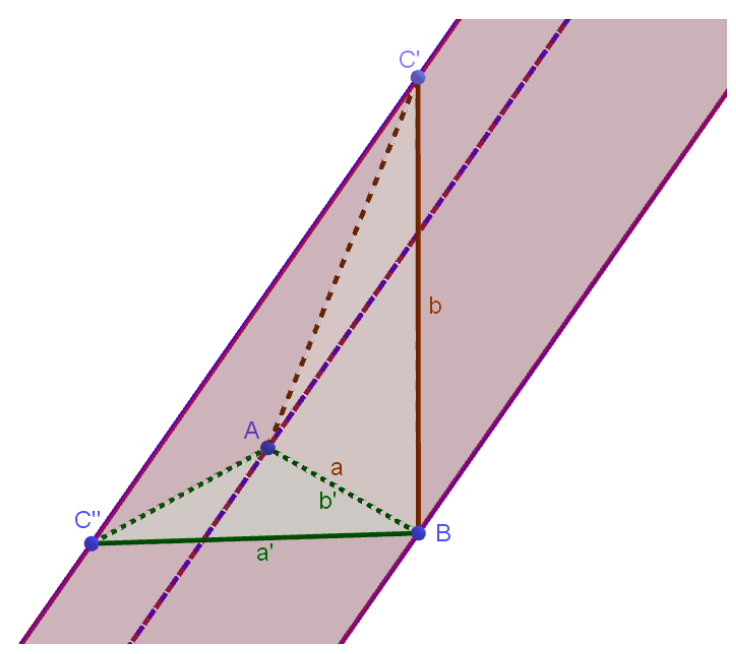

Task. Moscow Verbal Olympiad in Geometry 2006

The base of the pyramid is a convex quadrangle. Does there necessarily exist a section of this pyramid that does not intersect the base and is an inscribed quadrangle?

\section{Solution}

Let $V$ is the top of the pyramid, $A B C D$ is its base (see Fig. a). If the sum of the opposite angles of the quadrilateral $A B C D$ is equal to $\pi$, then it is enough to draw a section parallel to it. Otherwise, we can assume that the sum of the angles $A$ and $C$ is greater than $\pi$. Take points $A$ ', $B^{\prime}, D^{\prime}$ on the edges $A V, B V, D V$, respectively, and let $C^{\prime}$ be the point of intersection of the plane $A^{\prime} B^{\prime} D^{\prime}$ ' with the edge $C V$. It is enough to find such $A^{\prime}, B^{\prime}$ and $D^{\prime}$ that the sum of the angles $A^{\prime}$ and $C$ ' is less than $\pi$ (by "dragging" such a section into a section parallel to the base, at some moment we will get the sum of the angles $A^{\prime}$ ' and $C^{\prime}$ ' equal to $\pi$, that is, the section will be an inscribed quadrangle).

Take points $B^{\prime}$ and $D^{\prime}$ at the same height. Since the direction of the segment $B^{\prime} D^{\prime}$ is fixed, its angle $\alpha>0$ with the $B C V$ plane is also fixed, and $D^{\prime} B^{\prime} C^{\prime} \geq \alpha$. Similarly, the angle $B^{\prime} D^{\prime} C^{\prime}$ is at least some $\beta>0$. Therefore, $\angle B^{\prime} C^{\prime} D^{\prime} \leq \pi-(\alpha+\beta)<\pi$. If now we choose $B^{\prime}$ and $D^{\prime}$ close enough to the vertex of $V$, then the angle $B^{\prime} A^{\prime} D^{\prime}$ will be close to 0 , so its sum with the angle $B^{\prime} C^{\prime} D^{\prime}$ will be less than $\pi$. 


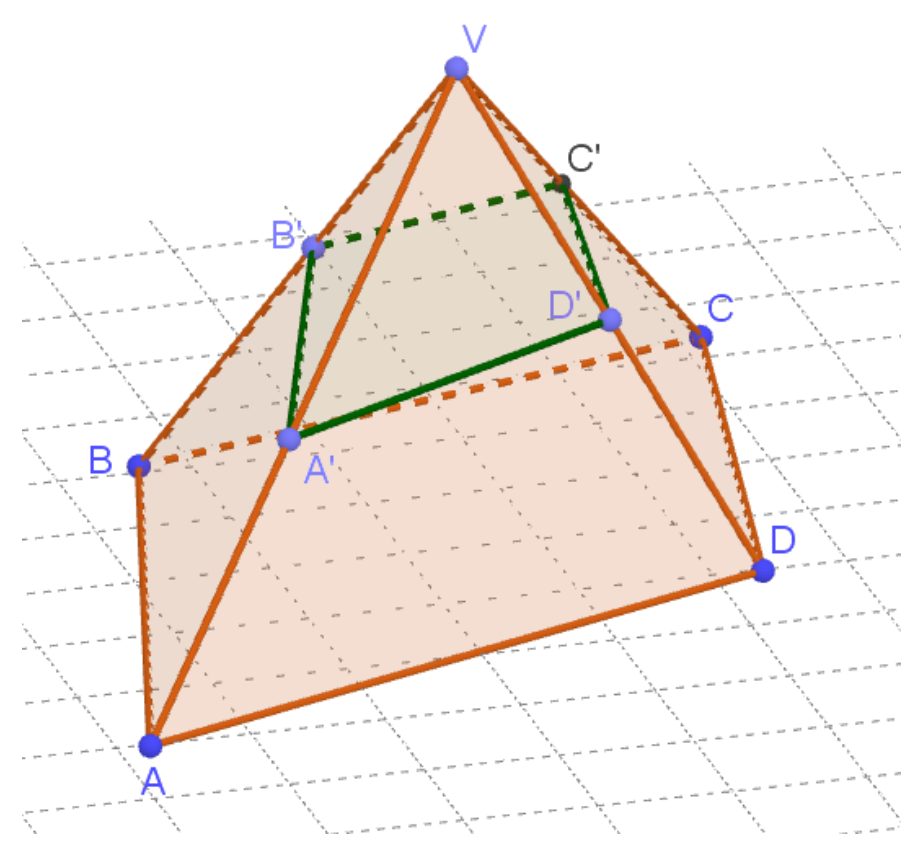

Task. All-Russian Olympiad in Mathematics 2008-2009

In the triangular pyramid $A B C D$, all flat angles at the vertices are not straight lines, and the intersection points of the heights in triangles $A B C, A B D, A C D$ lie on one straight line. Prove that the center of the described sphere of the pyramid lies in the plane passing through the midpoints of the edges $A B, A C, A D$.

\section{Solution}

Let $A B_{1}, A C_{l}, A D_{1}$ be the heights of edges $A C D, A B D, A B C$. The intersection points of the heights of these faces lie on straight lines $A B_{1}, A C_{l}, A D_{1}$ and are different from point $A$. Since they lie on one straight line $\ell$, then the straight lines $A B_{1}, A C_{l}, A D_{l}$ lie in the plane $\alpha$, which contains $\mathcal{E}$ and $A$ (it is clear $A$ does not lie at $\ell$ ). Then points $B_{1}, C_{l}, D_{l}$ lie at the straight line of intersection of planes $\alpha$ and $B C D$.

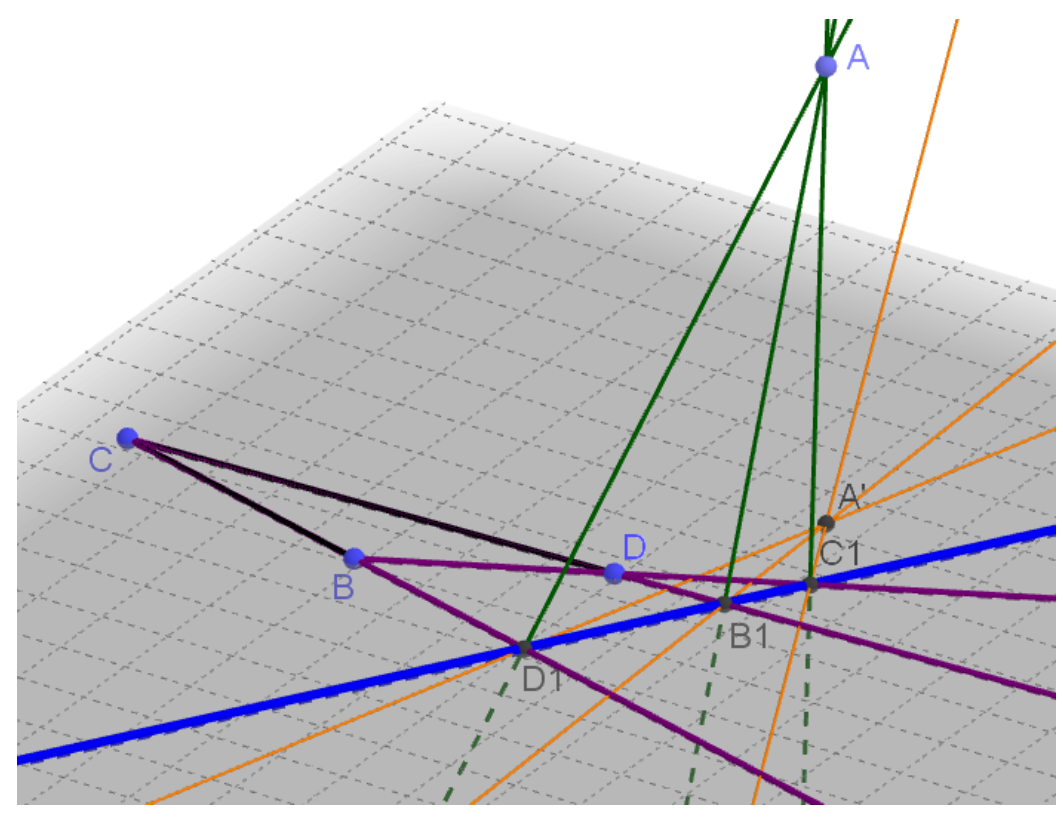




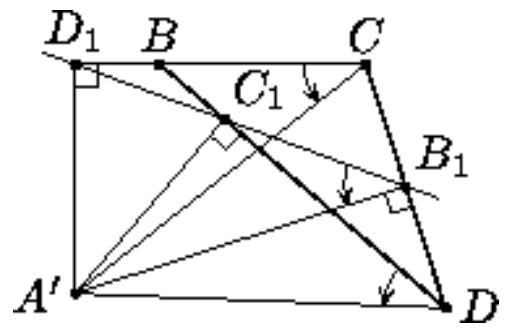

Let $A^{\prime}$ be the projection of point $A$ onto the plane $B C D$. Then, following the theorem of three perpendiculars, points $B_{l}, C_{l}, D_{l}$ are projections of $A$ ' to straight lines $C D, B D, B C$. Then points $A^{\prime}, \mathrm{C}, B_{1}, D_{l}$ lie at the same circle (with dia $A^{\prime} C$ ), and points $A^{\prime}, \mathrm{D}, B_{1}, C_{l}$ lie at the same circle (with dia $\left.A^{\prime} D\right)$. Hence $\angle\left(B C, A^{\prime} C\right)=\angle\left(D_{l} C, A^{\prime} C\right)=\angle\left(D_{l} B_{1}, A^{\prime} B_{l}\right)=\angle\left(C_{l} B_{l}, A^{\prime} B_{l}\right)=\angle$ $\left(C_{1} D, A^{\prime} D\right)=\angle\left(B D, A^{\prime} D\right)$ (here through $\angle(a, b)$ denote the angle from the straight line $a$ to the straight line $b$, counted counterclockwise; this angle is calculated up to the addition of a number of the form of $\pi k$, where $k$ is an integer). From the equation $\angle\left(B C, A^{\prime} C\right)=\angle\left(B D, A^{\prime} D\right)$ it follows that the point $A$ ' lies on the circumcircle of a triangle $B C D$ and, therefore, on the described sphere $S$ of pyramid $A B C D$.

Then the center $O$ of the sphere $S$ is in the plane $\beta$, which is the midpoint perpendicular to $A A^{\prime}$. It is clear that the midpoints of the edges $A B, A C, A D$ are also in $\beta$ (since the triangles are $A B A^{\prime}, A C A^{\prime}, A D A^{\prime}$ rectangular). This was what had to be proved.

Note 1. Let's lower the perpendiculars from an arbitrary point $A$ ', which is in the plane $B C D$, to the straight lines $B C, C D, B D$. Their bases lie on one straight line if and only if $A^{\prime}$ lies on the circumcircle of a triangle $B C D$. This straight line is called Simson's line of point $A^{\prime}$ '.

Note 2. Tetrahedrons satisfying the condition of the problem do exist.

\section{Discussion of the results}

The pedagogical experiment was carried out based on the winter and summer shifts of the Olympic schools at MIPT in 2017-2019, as well as on the subject shifts at the Strategy Center for Gifted Children Support (Lipetsk). Training in groups of olympiad training was held by participants of the above shifts from the senior classes with a numerical strength of 200 schoolchildren. The hypothesis was tested: the developed mental activity for the development of geometric concepts, expressed in the formation of the operations "transformation of initial images" and "orientation in the theoretical space", is provided by a specially organized educational activity in an electronic educational environment based on 3D graphics of the GeoGebra environment and a developed system of tasks in within the elective course "Problems of solid geometry and computer graphics" for schoolchildren in grades 10-11. The purpose of the experiment was to assess the qualitative and quantitative changes in motivational and operational characteristics that characterize the dynamics of the development level of mental activity in mastering the methods of action with geometric concepts.

Table 3

Diagnostic tasks for assessing the cognitive level of mental activity development in mastering geometric concepts

\begin{tabular}{|c|l|c|c|}
\hline Phases & Levels & $\begin{array}{c}\text { Characteristics of } \\
\text { actions }\end{array}$ & $\begin{array}{c}\text { Characteristics of the skills } \\
\text { corresponding to this level }\end{array}$ \\
\hline
\end{tabular}




\begin{tabular}{|c|c|c|c|}
\hline 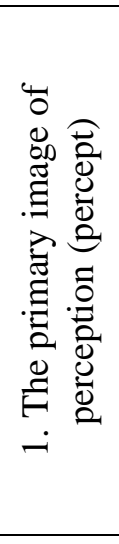 & $\begin{array}{l}\text { 1. Low reproductive level } \\
\text { Creating an image }\end{array}$ & $\begin{array}{l}\text { Structuring of a } \\
\text { visually perceived } \\
\text { object is the } \\
\text { selection of } \\
\text { individual elements, } \\
\text { spatial and metric } \\
\text { relationships of a } \\
\text { figure as a carrier of } \\
\text { a concept, its } \\
\text { species-level } \\
\text { identification. }\end{array}$ & $\begin{array}{l}\text { The ability to create two- } \\
\text { dimensional and three-dimensional } \\
\text { images of objects by analytical } \\
\text { expression or constructive } \\
\text { description - to perform a drawing } \\
\text { or a computer model, supplement } \\
\text { them with new elements following } \\
\text { the specified conditions, correctly } \\
\text { reflect their shape and size. The } \\
\text { images are characterized by static, } \\
\text { fragmented, flexible, in some cases, } \\
\text { original, have expressive details. }\end{array}$ \\
\hline 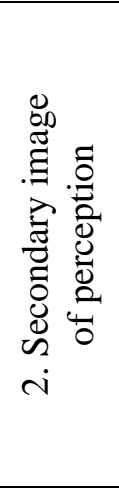 & $\begin{array}{l}\text { 2. Average reproductive } \\
\text { level } \\
\text { representation (typing) }\end{array}$ & $\begin{array}{l}\text { The image is freed } \\
\text { from "chaining" to a } \\
\text { single object and } \\
\text { can be a generalized } \\
\text { image of a whole } \\
\text { class of objects. }\end{array}$ & $\begin{array}{l}\text { Ability to create two-dimensional } \\
\text { and three-dimensional images of } \\
\text { objects, supplement a drawing or a } \\
\text { computer model with new elements, } \\
\text { correctly reflect their shape and } \\
\text { size, as well as spatial placement } \\
\text { relative to a given frame of } \\
\text { reference. The images are holistic, } \\
\text { diverse, original, quickness and } \\
\text { flexibility of thinking are } \\
\text { manifested, objects are "revived". }\end{array}$ \\
\hline \multirow{3}{*}{ 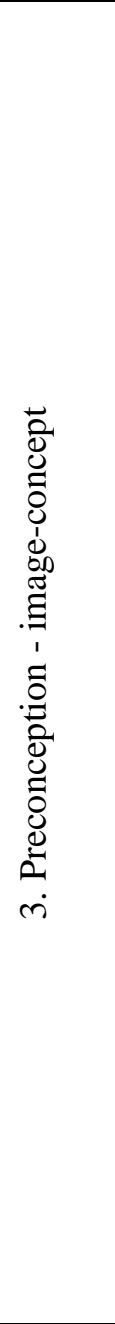 } & $\begin{array}{l}\text { 3. High reproductive level } \\
\text { Using } \\
\text { the image ("movement") }\end{array}$ & $\begin{array}{l}\text { The original image, } \\
\text { created on a } \\
\text { graphical visual } \\
\text { basis, is modified } \\
\text { following the } \\
\text { conditions of the } \\
\text { task: mental } \\
\text { rotation, movement } \\
\text { of the image by } \\
\text { changing the } \\
\text { starting point. }\end{array}$ & $\begin{array}{l}\text { The ability to change the spatial } \\
\text { position of the images available in } \\
\text { the presentation - to carry out their } \\
\text { movement without affecting the } \\
\text { structural features. It does not occur } \\
\text { any structural changes geometrical } \\
\text { figure - it simply moves in the space } \\
\text { - parallel translation, rotation, and a } \\
\text { central axial symmetry concerning } \\
\text { symmetry plane, homothety } \\
\text { parallel, and orthogonal projection. }\end{array}$ \\
\hline & $\begin{array}{l}\text { 4. Low productive level } \\
\text { Using the image } \\
\text { ("reconstruction") }\end{array}$ & $\begin{array}{l}\text { Changing the } \\
\text { structure of the } \\
\text { image in the view; } \\
\text { mental regrouping } \\
\text { of the constituent } \\
\text { elements of the } \\
\text { image using the } \\
\text { operations of } \\
\text { superposition, } \\
\text { alignment, } \\
\text { dissection, etc. }\end{array}$ & $\begin{array}{l}\text { The ability to change not only the } \\
\text { position of the original image in } \\
\text { space but also its structure and } \\
\text { composition. The breadth of image } \\
\text { manipulation is manifested, } \\
\text { expressed in the freedom to use } \\
\text { various images. The structure of the } \\
\text { original image is being transformed. } \\
\text { Unlike movement, here the mental } \\
\text { image undergoes a single } \\
\text { modification of its structure - } \\
\text { cutting, folding, etc. }\end{array}$ \\
\hline & $\begin{array}{l}\text { 5. Average productive level } \\
\text { Using the image } \\
\text { ("composition") }\end{array}$ & $\begin{array}{l}\text { A chain of mental } \\
\text { operations aimed at } \\
\text { manipulating an } \\
\text { image, in which a } \\
\text { sequence "intermediate" of } \\
\text { images appears. }\end{array}$ & $\begin{array}{l}\text { Ability to change the original image } \\
\text { in terms of spatial position and } \\
\text { structure at the same time, } \\
\text { repeatedly. A geometric object is } \\
\text { repeatedly modified, while also } \\
\text { moving in space. }\end{array}$ \\
\hline
\end{tabular}




\begin{tabular}{|c|c|c|c|}
\hline \multirow{4}{*}{ 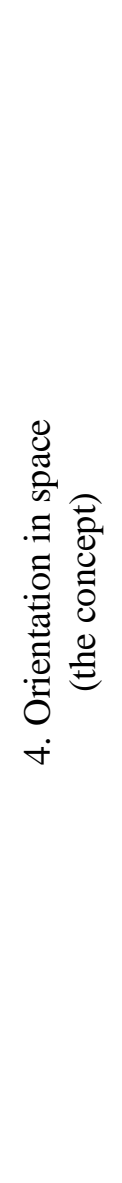 } & $\begin{array}{l}\text { 6. High productive level } \\
\text { Orientation in space ("from } \\
\text { oneself") }\end{array}$ & $\begin{array}{l}\text { Determination of } \\
\text { the location or } \\
\text { direction of } \\
\text { movement of an } \\
\text { object in space } \\
\text { through external } \\
\text { (visual) landmarks. }\end{array}$ & $\begin{array}{l}\text { The ability to navigate when the } \\
\text { starting-point coincides with the } \\
\text { schoolchild. }\end{array}$ \\
\hline & $\begin{array}{l}\text { 7. Low productive and } \\
\text { creative level Orientation in } \\
\text { space (from an a a } \\
\text { independently selected } \\
\text { reference point) }\end{array}$ & $\begin{array}{l}\text { Determination of } \\
\text { the location or } \\
\text { direction of } \\
\text { movement of an } \\
\text { object in the space } \\
\text { of internal } \\
\text { (kinesthetic) } \\
\text { landmarks. }\end{array}$ & $\begin{array}{l}\text { The ability to navigate in the case } \\
\text { when the schoolchild chooses the } \\
\text { most convenient starting point. }\end{array}$ \\
\hline & $\begin{array}{l}\text { 8. Average productive and } \\
\text { creative level } \\
\text { Orientation in space (from } \\
\text { an objectively specified } \\
\text { reference point) }\end{array}$ & $\begin{array}{l}\text { Determination of } \\
\text { the location or } \\
\text { direction } \\
\text { movement of an } \\
\text { object in space } \\
\text { through visceral } \\
\text { landmarks. }\end{array}$ & $\begin{array}{l}\text { The ability to navigate when the } \\
\text { starting point is fixed by the } \\
\text { condition of the problem. }\end{array}$ \\
\hline & $\begin{array}{l}\text { 9. High productive and } \\
\text { creative level } \\
\text { Orientation in space (from a } \\
\text { dynamically changing } \\
\text { reference point). }\end{array}$ & $\begin{array}{l}\text { Determining the } \\
\text { location or direction } \\
\text { of movement of an } \\
\text { object in space. }\end{array}$ & $\begin{array}{l}\text { Ability to navigate when the } \\
\text { reference point moves. }\end{array}$ \\
\hline
\end{tabular}

Empirical research requires that the identified levels of the development of mental activity have a category of measure. In this regard, an ordinal scale for assessing levels was built, comparing a quantitative indicator (score) to each qualitative indicator (mental skill). Indicators of the low, medium, and high levels were assigned 1,2, and 3 points, respectively, which made it possible to determine in the experimental group the percentage of schoolchildren with one or another level of spatial thinking. The results of the diagnostic slice shown in Table 5. Obviously, at the initial stage of education in the experimental group, the percentage of schoolchildren with a low and medium level is quite high.

Table 5

Levels of mental activity development in mastering geometric concepts before the start of experimental training $(\%)$

\begin{tabular}{|l|l|l|}
\hline Low & Average & High \\
\hline 39 & 59 & 2 \\
\hline
\end{tabular}

The results of the control slice carried out after studying the course are reflected in Table 6.

Table 6

Levels of mental activity development in mastering geometric concepts after the experimental training $(\%)$

\begin{tabular}{|l|l|l|}
\hline Low & Average & High \\
\hline 23 & 65 & 12 \\
\hline
\end{tabular}


To compare the level of development before and after experimental training, the Wilcoxon T-test was used (Table 7), which allows comparing the indicators measured under different conditions on the same sample. The following hypotheses were put forward:

$\mathrm{H} 0$ - the intensity of shifts towards a decrease in the level of development does not exceed the intensity of shifts towards an increase;

$\mathrm{H} 1$ - the intensity of shifts towards a decrease in the level of development exceeds the intensity of shifts towards an increase.

Table 7

Calculation of the Wilcoxon T-test

\begin{tabular}{|c|c|c|c|c|}
\hline $\begin{array}{l}\text { Test } \\
\text { subject } \\
\text { number }\end{array}$ & $\begin{array}{l}\text { The } \\
\text { number of } \\
\text { points for the } \\
\text { ascertaining } \\
\text { slice C1 }\end{array}$ & $\begin{array}{l}\text { The } \\
\text { number of } \\
\text { points for the } \\
\text { control slice } \\
\text { C2 }\end{array}$ & $\Delta=\left|C_{1}-C_{2}\right|$ & $\begin{array}{c}\text { Rank } \\
\text { number } \Delta\end{array}$ \\
\hline 1 & 34 & 38 & 4 & 6.5 \\
\hline 2 & 50 & 53 & 3 & 5 \\
\hline 3 & 45 & 46 & 1 & 2 \\
\hline 4 & 32 & 42 & 10 & 15 \\
\hline 5 & 18 & 27 & 9 & 13.5 \\
\hline 6 & 50 & 48 & 2 & 3.5 \\
\hline 7 & 16 & 24 & 8 & 12 \\
\hline 8 & 30 & 23 & 7 & 10.5 \\
\hline 9 & 24 & 29 & 5 & 8 \\
\hline 10 & 22 & 20 & 2 & 3.5 \\
\hline 11 & 20 & 26 & 6 & 9 \\
\hline 12 & 39 & 51 & 12 & 16 \\
\hline 13 & 36 & 50 & 14 & 17 \\
\hline 14 & 49 & 45 & 4 & 6.5 \\
\hline 15 & 16 & 23 & 7 & 10.5 \\
\hline 16 & 19 & 28 & 9 & 13.5 \\
\hline 17 & 46 & 46 & 0 & 1 \\
\hline
\end{tabular}

The sum of the ranks of atypical (negative) shifts is the empirical value of the T-test: $T_{\text {эми }}=\sum R_{\text {-" }^{\prime}}=24$

. According to the table of critical values of the Wilcoxon test, the authors determine the critical value of $\mathrm{T}$ for $\mathrm{n}=17$. At a significance level of $0.05 \mathrm{~T}$-test $=41$, and at a significance level of $0.01-\mathrm{T}$-test $=27$. It is known that a typical (positive) shift is reliably dominant in intensity, if $T_{\text {эил }} \leq T_{0,05}$, and even more reliably dominant in intensity, if $T_{\text {эми }} \leq T_{0,01}$. In this case $T_{\text {эми }} \leq T_{0,01}$, therefore, the shift in the level of development of the spatial component of mental activity towards an increase is reliably prevailing.

\section{Conclusion}

The study demonstrated that it is impossible to rely solely on declarative knowledge in the development of conceptual activity in geometry. On the contrary, it is necessary to provide the formation of procedural knowledge (in the form of algorithms, techniques, and methods of operating with geometric concepts) through task material and to teach schoolchildren such actions, which would facilitate the transition of declarative knowledge into procedural. On the other hand, it is necessary to ensure the formation of a value-based knowledge system, which creates the effect of a schoolchild's "personal presence" in the process of mastering a scientific concept.

The use of an interactive geometric environment provides a qualitative uniqueness of activities on mastering figurative-spatial methods of action with geometric concepts, the ease and 
speed of interrelated processes of creating and using a spatial image, and the richness and variety of spatial images that arise on the dynamic visual basis of 3D graphics. The content of the activity, thanks to the capabilities of the GeoGebra dynamic environment, includes both substantive actions and integral operations. Thus, considering that the main goal of experimental teaching is the mastery by schoolchildren of the free usage of spatial images, the authors did not classify a priori schoolchildren who mastered the tasks of creating an image to the reproductive type, but to using the image, subject to abstraction from the initial visualization to the productive one, considering both activities productive.

The development of schoolchildren' activity in mastering figurative-spatial interaction with geometric concepts occurred under the direct influence of teaching. However, this process is complex and internally contradictory. The structure of this kind of activity contains elements of different nature. The complexity and abundance of factors ensuring their formation determine the peculiarities of development. The assessment of the development level of schoolchildren' activity in mastering figurative-spatial interaction with geometric concepts was carried out comprehensively, considering its complex structure, based on indicators that are internally and closely interrelated. The most significant factors in the effectiveness of developing mental activity in mastering figurative-spatial interaction with geometric concepts are typifying actions that make up the structure of the activity component of geometric concepts (object actions, real, formal, and integral operations); the allocation of a holistic mental structure that ensures the development of figurative-spatial interaction with geometric concepts, in which the image is the main operational unit; using the GeoGebra dynamic system as a component of the electronic educational environment; the formation of a value-based attitude, provided by substantive and methodological means along two lines - historicity and applied orientation.

\section{Acknowledgments}

The study is completed within the framework of the grant No. 19-313-90018 of the Russian Foundation for Basic Research for implementing the scientific project "Methodological support of the process of mastering geometric concepts at school in the electronic educational environment", supported by the Russian Foundation for Basic Research based on the competitive selection for the best projects of fundamental scientific research by postgraduate students.

\section{References:}

1. Arbain, N., \& Shukor, N. A. (2015). The effects of GeoGebra on Schoolchildren achievement. Procedia-Social and Behavioral Sciences, 172, 208-214.

2. Aydin, H., \& Monaghan, J. (2011). Bridging the divide--Seeing mathematics in the world through dynamic geometry. Teaching Mathematics and Its Applications: An International Journal of the IMA - 30(1) - 1-9.

3. Fahlberg-Stojanovska, L, \& Stojanovski, V. (2009). GeoGebra- freedom to explore and learn. Teaching Mathematics and Its Applications: An International Journal of the IMA $-28(2)-49-54$.

4. Hall, J., \& Chamblee, G. (2013). Teaching algebra and geometry with GeoGebra: Preparing pre-service teachers for middle grades/secondary mathematics classrooms. Computers in the Schools, 30(1-2), 12-29.

5. Ochkov, V. F., \& Bogomolova, E. P. (2015). Teaching Mathematics with Mathematical Software. Journal of Humanistic Mathematics, 5(1), 265-285.

6. Takaci, D., Stankov, G., \& Milanovic, I. (2015). The efficiency of learning environment using GeoGebra when calculus contents are learned in collaborative groups. Computers \& Education, 82, 421-431.

7. Thambi, N., \& Eu, L. K. (2013). Effect of schoolchildren' achievement in fractions using GeoGebra. SAINSAB, 16, 97-106.

8. Zakaria, E., \& Lee, L. S. (2012). Teacher's perceptions toward the use of GeoGebra in the teaching and learning of Mathematics. Journal of Mathematics and Statistics, 8(2), 253-257. 
9. Zengin, Y., Furkan, H., \& Kutluca, T. (2012). The effect of GeoGebra dynamic mathematics software on schoolchild achievement in teaching trigonometry. Procedia: Social and Behavioral Sciences, 31, 183-187. doi:10.1016/j.sbspro.2011.12.038

10. Aslanyan, I.V. (2006). Methodology for controlling the development of spatial thinking of schoolchildren in grades 5-6 of secondary school in the study of geometric material from the fusionism standpoint. Extended abstract of Cand. Sci. (Ped.) Dissertation. Astrakhan: SSU.

11. Asmolov, A.G. (2012). Optics of education. Moscow: Education.

12. Breus, I.A. (2014). Diagnostics of the state of topical problems of mathematical education: collective monograph. Rostov-on-Don: Publishing house of the Southern Federal University.

13. Vekker, L.M. (1976). Mental processes. Thinking and intelligence. Vol.2. Leningrad: Publishing house of Leningrad State University.

14. Vering, Yu.I. (1989). Forming schoolchildren' skills to build evidence. Extended abstract of Cand. Sci. (Ped.) Dissertation. Riga.

15. Vilenkin, N.Ya., Abaidulin, S.K., Tavartkiladze, R.K. (1984). Definitions in the school course of mathematics and methods of working on them. Mathematics at school. No. 4.

16. Voistinova, G.Kh. (2000). Tasks for building as a means of forming the methods of mental activity of primary school schoolchildren. Extended abstract of Cand. Sci. (Ped.) Dissertation. Moscow.

17. Vygotsky, L.S. (2016). Collected works: In 6 volumes. Vol. 2: Thinking and speech. Moscow: Pedagogika.

18. Yermak, E.A. (2003). Development of the geometric component of the natural-scientific picture of the world in high school schoolchildren. Bulletin of the Herzen Russian State Pedagogical University. Saint-Petersburg: Publishing house of the Herzen Russian State Pedagogical University. Vol. 3, No. 6, pp. 204-214.

19. Zinchenko, V.P., Munipov, V.M., Gordon, V.M. (1973). Research of visual thinking. Questions of psychology. No. 2, pp. 3-14.

20. Kaplunovich, I.Ya. (1978). On the structure of spatial thinking in solving mathematical problems. Questions of psychology, No. 3, pp. 75-84.

21. Gusev, V.A., Orlov, V.V., Panchishin, V.A. (2004). Geometry teaching methodology: a textbook for schoolchildren of higher pedagogy institutions. Moscow: "Academy".

22. Piaget, J. (1966). How children form mathematical concepts. Questions of psychology. No. 4, pp. 121-126.

23. Podaev, M.V. (2009). Dynamic visualization of geometric concepts as a means of developing the creation of spatial representations of the pyramid of adolescents.

24. Podaeva, N.G. (2014). Sociocultural communication in teaching geometry to younger adolescents. The Emissia. Offline Letters. Article No. 2207. URL: http://www.emissia.org/offline/2014/2207.htm

25. Podaeva, N.G., Podaev, M.V. (2013). Socio-cultural content of school mathematics education: thought-activity technologies. The Emissia. Offline Letters. No. 1 (January). Article No. 1948. URL: http://www.emissia.org/offline/2013/1948.htm

26. Podkhodova, N.S. (1997). Geometry is very in space. Grade 5: Textbook. SaintPetersburg: Publishing house "Goland".

27. Talyzina, N.F. (1984). Management of the process of assimilation of knowledge. Moscow: Publishing house of Moscow State University.

28. Ustilovskaya, A.A. (2008). Psychological mechanisms of overcoming the symbolic naturalization of the ideal content of geometric concepts. Dissertation of Cand. Sci. (Psych.). Moscow.

29. Kholodnaya, M.A. (2002). The psychology of intelligence. Research paradoxes. SaintPetersburg: Peter.

30. Sharygin, I. (2004). Does the School of the 21st Century Need Geometry? Mathematics construction at school. No. 4. Pp. 72-78.

31. Shemyakin, F.N. (1968). Some theoretical problems of the study of spatial perceptions and representations. Questions of psychology, No. 4.- pp. 18-28. 
32. Shchedrovitsky, G.P. (1995). Selected Works. Moscow: School of Cultural Policy.

33. Yakimanskaya, I.S. (1980). Development of spatial thinking of schoolchildren. Moscow: Pedagogika.

34. Beloshistaya, A.V. (2006). A new methodological system for the development of spatial thinking of schoolchildren in grades I - IV. Questions of psychology. No. 1. Pp. 16-22.

35. Vasilenko, A.V. (2015). Systematization of tasks for the development of spatial thinking of schoolchildren. Modern problems of science and education. No. 2. Pp. 460-470.

36. Dalinger, V.A. (2016). Cognitive-visual approach to teaching mathematics as a factor of $\mathrm{s}$ schoolchildren success in the educational process. International Journal of Experimental Education. No. 5/2. Pp. 206-209

37. Vekker, L.M. (2000). Psyche and reality: Unified theory of mental processes. Moscow: Meaning: Per Se.

38. Rubinshtein, S.L. (2002). Fundamentals of General Psychology. Saint-Petersburg: Peter.

39. Kadayas, H.-M.H. (1985). Features of spatial thinking of schoolchildren with artistic and mathematical inclinations. Extended abstract of Cand. Sci. (Ped.) Dissertation. Moscow.

40. Pasani, C.F. (2019). Analyzing Elementary School Students Geometry Comprehension Based on Van Hiele's Theory. Journal of Southwest Jiaotong University, 54(5). https://doi.org/10.35741/issn.0258-2724.54.5.31

Note: The study is completed within the framework of the grant No. 19-313-90018 of the Russian Foundation for Basic Research for implementing the scientific project "Methodological support of the process of mastering geometric concepts at school in the electronic educational environment", supported by the Russian Foundation for Basic Research based on the competitive selection for the best projects of fundamental scientific research by postgraduate students. 